\title{
Digital transformation in the business: a solution for developing cash accounting information systems and digitizing documents
}

\author{
Manh Tuan Nguyen ${ }^{1}$, Quoc Hung Nguyen ${ }^{1, *}$, Thi Hang Nguyen ${ }^{2}$
}

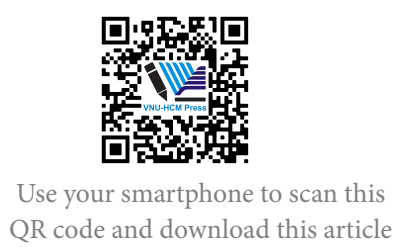

QR code and download this article
${ }^{1}$ School of Business Information Technology University of Economics Ho Chi Minh City, Ho Chi Minh City 700000, Vietnam

${ }^{2}$ Faculty of Economic Information System University of Information and Communication technology Thai Nguyen, Vietnam

\section{Correspondence}

Quoc Hung Nguyen, School of Business Information Technology University of Economics Ho Chi Minh City, Ho Chi Minh City 700000, Vietnam

Email: hungngq@ueh.edu.vn

History

- Received: 2021-03-02

- Accepted: 2021-05-09

- Published: 2021-05-21

DOI : 10.32508/stdj.v24i2.2526

\section{Check for updates}

\section{Copyright}

(c) VNU-HCM Press. This is an openaccess article distributed under the terms of the Creative Commons Attribution 4.0 International license.

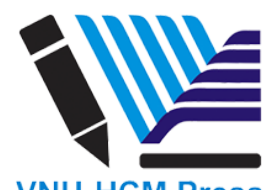

\begin{abstract}
Digital transformation is becoming an inevitable trend, having a profound impact on business activities, processes, and improving the operational efficiency of businesses. In enterprises, especially small and medium-sized enterprises, accounting professions are mainly still handled manually on books and documents. They have not standardized the professions, especially those that arise in the course of operation. This makes it difficult for accounting such as accounting work gradually increases, the handling of work is delayed, easily confused and errors... Leading to limiting the development and expanding the size of the business. The problem for each business is the need to automate some accounting operations to adapt to the trend and context of digital transformation, contributing to improving the competitive efficiency of the business. Stemming from the above difficulties, the research will find solutions to help businesses approach and apply processing operations professionally towards the formation of digital businesses. The article will focus on building cash accounting modules and handling professional accounting processes to implement digital transformation in enterprises. The operations mentioned in the article include building the professional process of cash accounting, controlling cash collection — spending, the process of digitizing documents stored at the enterprise, etc... The article will propose how to process data and make reports required by managers for decision-making based on invoices and handling arising transactions.

Key words: Digital transformation in enterprises, business efficiency, accounting system, cash accounting, competitive advantages of enterprises, digitalization of documents
\end{abstract}

\section{INTRODUCTION}

In digital transformation, cash accounting is considered one of the most important for businesses. To maintain business operations and achieve optimal efficiency, managers must do an excellent job of managing cash because it is the blood that feeds the existence of the business itself. Although there are many modern accounting blankets for businesses, however, in small and medium-sized enterprises, this is still quite difficult because businesses' specialization has not really been focused. Although in small and mediumsized enterprises, due to the simple process characteristics, less personnel should perform digital transformation than large-scale businesses. Therefore, businesses need to take advantage of the opportunity to implement digital transformation to take advantage of standardized business processes and not spend a lot of time on the processing stages that arise. However, to implement digital transformation, businesses must pay attention to the initial foundational issue of designing and standardizing processes; each person in the enterprise's apparatus must be knowledgeable about digital transformation.
Digital transformation in enterprises is understood as transforming the way businesses operate based on information technology. The essence of digital transformation in enterprises must start from the transformation of the business system of the enterprise, but at the core is to change the working process, the way these businesses work. The purpose of digital transformation is to help businesses create a competitive advantage in the context of global integration and the strong development of the industrial revolution 4.0.

To successfully implement a digital transformation, businesses need to respond to their research and consider three important factors, namely cost, profitability and convenience, ease of application of business processes. For small and medium-sized enterprises, the cost of implementing digital transformation needs to be moderate because there are many tools with a cost of only a few hundred thousand / month that businesses can still automate accounting. Besides, the application of digital transformation for businesses is often interested in ease and convenience. That is, which tool is easy to apply first. In addition, an equally important factor is that digital transformation needs 
to affect the revenue of the business directly. Therefore, implementing digital transformation needs to be simple, save time, and focus too much manpower on avoiding causing losses to the business's revenue.

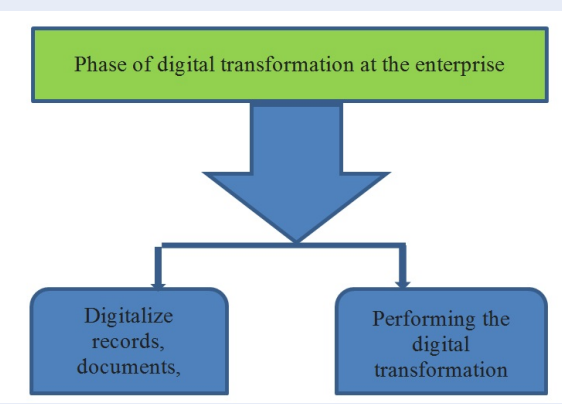

Figure 1: Phase of digital transformation at the enterprise (Source: Design by the authors).

At the stage of digitization of records, documents, and processes: This is the first stage in which businesses perform a digital transformation. This is a rather complicated and challenging period for businesses. At this stage, the business managers must be really determined to gradually get rid of the traditional business model and move to a digital business model, thereby having a specific investment strategy in technology and human resources, bringing the business into a new stage of development. At this stage, all enterprise documents are quite primitive, exist in the physical form that needs to be encoded into electronic information and stored in the online environment. Once determined to implement digital transformation at the enterprise, managers must choose and resolve towards a digital platform with basic pillars: One is digital infrastructure, including computers, internet, social networks, and fast media... The second is the mechanism and process for operating those facilities. The third is a digital-based business model, one of which is e-commerce. To do that, businesses must be really determined and have the right development strategy, so they will save time on data entry, search, and the types of printing costs in addition. At the same time, it will overcome the situation of storage space and minimize the loss and loss of data. It can be said that the digitization stage will create premeditation for businesses to go into the higher stages of digital transformation.

Next, there is an implementing digital transformation at enterprises. This is an important and decisive stage to success, requiring businesses to have investment strategies for research, technological innovation, and innovation. In addition, businesses need to train or recruit more high-quality human resources to operate digital technologies. After forming a planned and structured process to meet users' needs, the enterprise will use enterprise management software that supports eliminating the flaws that we create. From there, businesses will complete the digitization of data, change the entire workflow from a strong place to a top-to-bottom process, closely linked processes. High consistency in the implementation process will help businesses maintain and manage key activities, which is the key to promoting business performance. In addition, the digital transformation process is also implemented in a synced way to help businesses monitor the evaluation management process with data mining, enterprise efficiency management and reporting, towards improving work efficiency and enterprise management efficiency. In addition, it also helps businesses recognize financial positions, profit, and financial strength quickly.

Our contributions focus on (1) propose operational procedures in the development of cash accounting information systems towards digital transformation at the enterprise, (2) design a cash accounting professional process to perform digital transformation at the enterprise, (3) Designing the process of digitization of documents stored at enterprises.

Cash accounting has a direct impact on the quality and efficiency of management in small and medium enterprises. The construction of a cash accounting information system helps to provide information and check economic and financial activities at the enterprise. Currently, in Vietnam, small and medium enterprises contribute about $48 \%$ of GDP and create more than $50 \%$ of jobs for society. However, due to the small size of this type of business, the narrow market, and low competitiveness, investment capital is limited. Moreover, in the context of the current industrial revolution 4.0, small and medium enterprises often see technology as their weaknesses. Because they often do not have the financial ability to invest in modern and advanced technology equipment and associate with banks to perform accounting transactions and control accounting and financial operations. Therefore, accounting software is often the first choice for SMEs to automate their business processes. Accountants will no longer spend too much effort in classifying documents; handle each economic operation; record all kinds of accounting books. More importantly, businesses need to consider the standard presentation of their financial statements. Therefore, the development of a cash accounting information 
system will help businesses overcome difficulties, especially in finance, and still apply technology in corporate governance to participate in the global value chain.

\section{LITERATURE REVIEW AND RESEARCH METHODS}

The application of solutions, especially technological solutions to improve the efficiency of accounting work, has been studied by scientists. In 1972, Marshall, $1972^{1}$ raised the problem of theoretical background research and application of information systems to accounting work. By the 1980s, several great authors such as Otley, $1980^{2}$, Gordon \& Narayanan, $1984^{3}$ mentioned research on the relationship between accounting information systems and corporate governance. These studies have sparked and confirmed more clearly the existence of a new research direction. It is the combination of the application of information systems into accounting work in organizations and enterprises. Kim \& Lee, $1986{ }^{4}$ have confirmed more clearly the role of users, including businesses, to exploit the application of information systems and accounting and administration.

By the 1990s, research was increasingly promoted. A series of authors have given their studies to clarify the appropriateness of applying information systems to accounting and governance in enterprises such as Susanto, $2015^{5}$, Neogy, $2014^{6}$. The articles have emphasized the importance of setting up information systems for businesses. Accounting work in enterprises has a close association with information systems, facilitating the settlement of arising transactions, enterprise management, and administration $^{78910}$. Thereby contributes to overcoming crisis and bankruptcy incidents in enterprises, especially financial crises ${ }^{11}$. In particular, it is necessary to mention the research of Davenport, $1998^{12}$, Holland \& Light, $1999^{13}$, Nah, Zuckweiler, \& Lee-Shang Lau, $2003^{14}$ in the formation and implementation of ERP systems in enterprises. After that, Wheeler, Hunton, \& Bryant, $2004^{15}$, Azmi \& Sri, $2020{ }^{16}$, Grabski, Leech, \& Schmidt, $2011^{17}$, Ghasemi, Shafeiepour, Aslani, \& Barvayeh, $2011^{18}$ have had more in-depth studies on the influence and role of information systems on financial and accounting work in enterprises. At the same time, the studies also supplement and clarify more about the theoretical basis and relationship of information systems with ERP applied in enterprises. In 2015, Chalu, $2015^{19}$ analyzed the concept, stages of analysis, design, installation, implementation of information systems in the in-depth study to process transactions and control in information systems for application in enterprises. Research by Grabski et al., $2011^{17}$, Chalu, $2015^{19}$ on the application of information systems to the analysis of corporate risks, middle risk of business processes has shown 6 groups of factors affecting accounting and corporate governance in enterprises. Factors affecting accounting, corporate governance include: information systems, accounting procedures, business processes, information management, risk management, reporting system. Kumar K., Van Hillegersberg J. $(2000)^{20}$, Kwang S. W, Alain C. L, Ying-Mei L., Keng O. $(2009)^{21}$ in their studies have confirmed the success of the business when applying ERP and present experiences when applying this system in businesses. Cash accounting information system is considered as a subsystem of the management information system. In this system, processing operations for accounting purposes at the enterprise play a fundamental role, contributing to improving the efficiency of processing accounting operations. At the same time, it helps to improve the efficiency of corporate governance in the context of global integration and the remarkable development of the fourth industrial revolution.

The above articles have emphasized the aspect of learning about developing accounting information systems in enterprises. The above articles have emphasized the aspect of learning about developing accounting information systems in enterprises. This is the foundation for businesses to implement digital transformation. However, digital transformation is a relatively new problem for businesses. This is a long and complicated process with many different stages, so it is necessary to have research papers for businesses to refer to before deciding to implement digital transformation.

The above studies have emphasized learning about the formation and development of accounting information systems applied to enterprises. This is a basis or foundation for businesses to carry out digital transformation. However, digital transformation is a relatively new problem. This is a long and complex process with many different stages, so it is necessary to have research to create a reference base for businesses before deciding to implement digital transformation for their business.

To complete this paper, the authors used a combination of theoretical and experimental research methods. First, scientific information collection method is used to study documents and documents related to digital transformation and digital transformation in enterprises. The authors use analytical methods to 
assess the impact and the need to perform the digital transformation in businesses. To design and build models and operational processes, the authors use the method of analysis, system design to model the system of the professional work of cash accounting. From there, clarify the actors participating in the system and the information flows necessary for decisionmaking and control of accounting work.

\section{PROPOSING DIGITAL TRANSFORMATION PROCESSES AT BUSINESSES}

Bruce Weinelt, John Moavenzadeh (2017) 22 pointed out the nature of digital transformation consisting of three basic steps: data digitization, technologybased data system management, and application of data analysis technology for making decisions. However, before doing that, businesses need to detail the extra steps for a successful digital transformation.

Dr. Stephen J. Andriole (member of the Association of Business Technologies \& Digital Transformation Strategy) and Professor Thomas G. Labrecque at Villanova University, proposed digitizing businesses to undergo a 5-step process.

In fact, many Vietnamese enterprises have been successful when applying the 5-step model in digital transformation. Typical examples are VPBank, by applying a 5-step model in digital transformation, VPBank reduced the number of employees to 2,300 in 2019 (a decrease of $20 \%$ of the total number of employees). The number of employees working for VPBank's parent bank decreased from 11,466 people (early 2019) to 9,144 people (as of September 30, 2019). Based on the reference of scientists' studies and observing the successful implementation of the digital transformation model in Vietnamese enterprises, the authors have proposed a 5-step model of digital enterprise development.

Digital transformation is a development model suitable for businesses to apply the achievements of the industrial revolution 4.0. Digital transformation depends on financial capacity, technology, and enterprise readiness. To successfully implement a digital transformation, enterprises need to research carefully and prepare the necessary elements. To build certainty and safety for your business when it comes to digital transformation, specific implementation steps are required. Enterprises need to develop appropriate development strategies and have to come up with a roadmap for digital transformation.

- Digital transformation planning : This is the first job to implement the digital transformation process at the enterprise associated with the business leader. They need to identify what is happening in the organization and the development trends of the market to plan the right direction for their business. At this time, business leaders need to discuss unity and develop a specific, clear plan to be ready to adapt to the digital transformation process. With the intellectual contribution and strength of the leadership team, a complete plan will create the proactive, affirming the success of the business.

- Develop a detailed development strategy : Once a business plan has been developed and to implement the plans set out for the business, it is necessary to develop the appropriate business strategy to make the strategy a reality. To succeed, businesses need to refer to relevant documents on digital transformation or refer to businesses that have successfully implemented digital transformation to apply flexibly to their businesses. It is necessary to grasp carefully and based on the unique characteristics of your business to build the right strategy. Businesses need to understand, digital transformation is a comprehensive process, so the strategy can change at different stages of development of the business. In order for all employees in the organization to understand that digital transformation is an important activity, leaders need to clarify that digital transformation is a central strategy of the business. This needs to be demonstrated through the actions, plans of the company, and the establishment of strategic teams in digital transformation.

- Digitized documents and processes : It can be said that digitization is considered the most important task in the process of implementing digital transformation at the enterprise. At this stage, businesses need to digitized documents and processes to create the necessary conditions to carry out the digital transformation process. This is a stepping stone for businesses to re-evaluate their own ability to see if they are ready for digital transformation. Therefore, businesses need to review all documents and processes used to remove old and out-of-pocket elements to make adjustments accordingly. A suggestion for businesses to ensure the successful digital transformation is that they need to choose to apply techniques and technologies to digitize their documents and processes. In the current context, big data applications can be considered by businesses to perform data analysis with ERP systems to connect and share data 


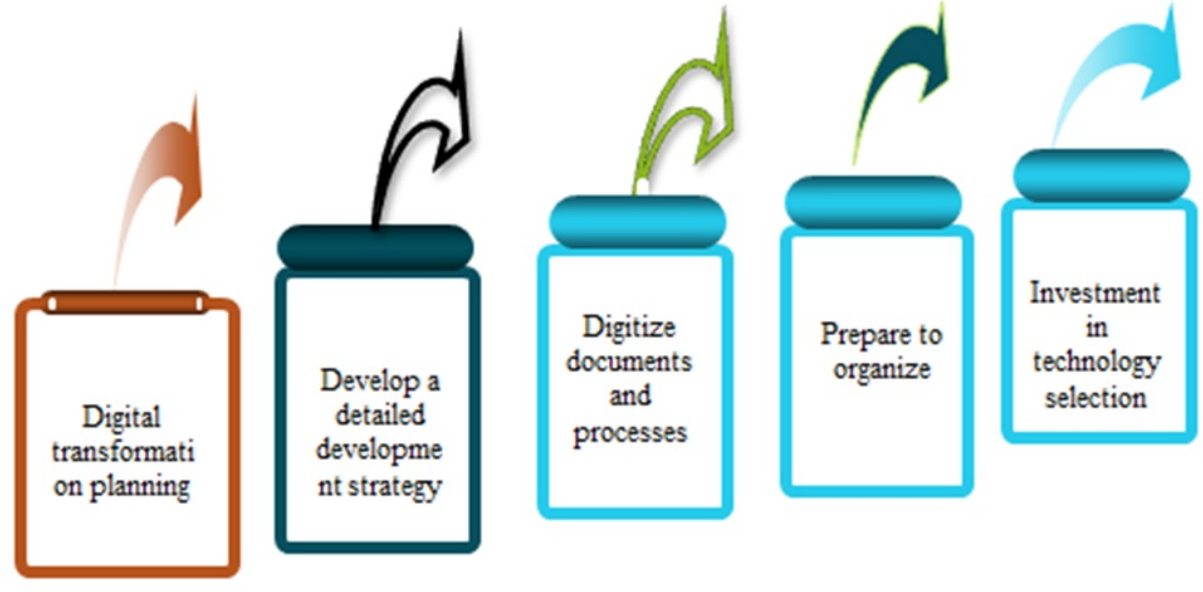

Figure 2: 5-step digital transformation model at the enterprise (Source: Design by the authors).

in the process of implementing digital transformation at the enterprise.

- Prepare to organize: To succeed, businesses need to pay attention to the time of factors: expertise, working environment, and how to use and arrange resources, called scientific labor organizations. In current conditions, the issue of scientific labor organization should be considered one of enterprise management focuses. The era of science and technology development leads to rapid changes in the entire social labor process. The amount of information is multiplied, the archives also increase, the demand for documents increases, the amount of work in agencies increases. Therefore, the requirements for staff qualifications are growing to adapt to the administrative period of industrialization and modernization. Still, facilities such as workplace area, working time, human resources, and successful digital transformation enterprises not only focus on expertise but also create a corporate culture and have the right way to use talents. Coming from the notion that each working position is an information clue in the business, each individual in daily work is directly involved in the reception and processing of information. The information received has many different forms, such as listening by phone, dialogue, indirectly such as receiving documents by fax, by post, by E-mail, by communication... Each type of information requires its form of processing. Information is classified into many different levels of processing such as urgent, confidential, essential, internal, universal... The information is quantified, estimated access frequency to base on which it is calculated the arrangement of working positions and specialized equipment in a reasonable way. During digital transformation, many situations can occur, including risks. Therefore, the preparation of the organization in the enterprise is essential. Employees need to be psychologically prepared to embrace changes both positive and risky. In addition to the expertise as the foundation for business development, managers need to pay attention to creating a positive working environment. With each working position, creating a comfortable, convenient and stable working environment or environment, employees will feel that themselves and their work are respected. They will have higher responsibility for assigned work, more excitement, and creativity when performing their tasks. Besides, the issue of allocating and using resources is also considered a key issue. The manager needs to appropriately perform the division of labor, i.e. division of labor to produce one or more certain products that must go through many details; many stages need many people to perform. There are two types of corporate labor division that can be referenced to apply flexibly to the organization. A separate division of labor, i.e. specialization of each stage of the production process in each company or factory. Assignment of social labor: towards specialization of each profession in society to create products. These products are no longer limited to the needs of the producers, but they are exchanged, purchased, circulated to users in society; at this 
time, such products are called goods. Simple division of labor is often applied in agencies with a simple, compact organizational structure, clear functions and duties, and basic tasks are performed independently of each other. The division of labor development is applied in agencies whose tasks need to be solved according to principles, sequence, or lines or in agencies whose tasks are only possible with the cooperation of many different positions and titles. This form of labor division also starts from the planning task of the agency after being analyzed by the leaders into specific tasks and assigned to their colleagues. The characteristic of this form of division of labor is that the work will be done in a line, the result of one person's work being the working condition of another. The implementation results of the final stage will be the overall results of the organization. The leader is responsible for checking and reporting the results to the superiors. One thing that needs to be done in parallel with the division of labor in the enterprise is the connection of the workforce together to create cooperation and cohesion between members and departments. Close labor cooperation creates favorable conditions for improving labor productivity, stimulating the spirit of emulation in production, saving living labor, and materialized labor. In addition, businesses can also form a temporary team consisting of key members, which have the main influence responsible for the digital transformation of the entire business.

- Investment in technology selection : For successful digital transformation, businesses need to pay special attention to technical factors. The assessment of technological readiness will help businesses realize their capabilities, thereby determining the level of technology upgrades and making appropriate choices with their capabilities. Survey results show that $80 \%$ of small and medium enterprises are currently facing many difficulties in building technology infrastructure in the digital transformation process. Because when digital transformation is applied, not all employees in an enterprise with technology skills and not technology deemed appropriate for the current development context will be chosen to use. The digital transformation process in the enterprise is becoming more and more popular, the technology platforms for the process also become easier and more optimal, creating good opportunities for businesses.
However, businesses also need to take the time to learn and choose the technology platform that is easy to apply, suitable for their financial capacity, and operating objects. The technology platform selected for application in enterprise digital transformation must be consistent with the specifics of the business, employee friendliness, and the current development context.

\section{RESULTS}

\section{Design a cash accounting professional pro- cess to perform digital transformation at thebusiness}

The accounting department's working results will contribute to high working efficiency, supporting the manager's strategic decision-making process for businesses. Helping businesses easily manage finance, accounting well control the accounting's actions according to predetermined processes. The functions of the accounting software will maximize the idea and establishment of cash accounting professional processes, from document preparation, revenue, and expenditure management to control of out-to-fund operations.

Each business has an appropriate amount of cash, an amount enough to pay interest and expenses. In addition, businesses also need cash to handle emergencies. To manage and accurately account for financial matters, the cash of the business should be centrally preserved in the budget. All cash receipts and payments at the enterprise must have valid invoices. The business director, and chief accountant must sign invoices. For duly checked invoices, the cashier collects or disburse the funds and re-sends signed receipts of the payee or payer. They are based on the receipts and expenses to record the fund book and make the fund statements together with the receipts and expenses to record the bookkeeping. The cashier is responsible for managing and importing the funds of cash, foreign currencies, gold, silver, and gemstones. Every day, the cashier must regularly make an inventory of the actual amount of funds. When the business has economic operations such as buying and selling goods... the accountant's job is to collect all relevant invoices and documents (output, input) to serve as a basis for the tax declaration and accounting. After the related invoices and vouchers have been compiled, the tax accountant must handle and check the legality, validity, and reasonableness of invoices. If there are any discrepancies, the cashier and accountant must reexamine themselves to determine the cause and propose timely measures. 
The process of constantly changing accounting:

Cash accounting invoices include receipts, payment receipts, receipts, advance requests, inventory records... in which mainly receipts, pay bills. It reflects the transactions related to the increase or decrease in cash of the business. The collection slip is used to determine the actual amount of cash entered into the fund. It is a basis for the cashier to collect, record the cash register and transfer it to the accountant for accounting entries. Every deposit is subject to a receipt. The receipt paid by the accountant (the person who made the ballot) is written in 3 copies, signed for certification by the payment accountant. If the enterprise applies machine accounting software, the receipt will be printed by the printer. Some businesses use word software to type and manually print receipts. Accounting invoices usually include receipts, payment receipts, advance requests, inventory records... In which mainly receipts, pay bills. Accounting invoices reflect transactions related to increasing or decreasing cash of the business. Receipt note: used to determine the actual amount of cash entered into the fund, which is the basis for the cashier to collect, record the treasury book and transfer it to the accountant for bookkeeping. Every deposit is subject to a receipt. Payment slip: used to determine the actual amount of cash to be spent, is the basis for the water fund to pay, record the fund book and transfer it to the bookkeeping accountant. Every expense must have a check.

The invoice rotation process is as follows:

Step 1: The accountant makes a receipt.

The receipt paid by the accountant (the person who made the ballot) is written in 3 copies, signed for certification by the payment accountant. If the enterprise applies machine accounting software, the receipt will be printed by the printer. Some businesses use word software to type and manually print receipts. The cashier passes the receipt to the chief accountant for review and submission to the director for approval. The payer transfers the receipt to the cashier to deposit and sign the receipt. The cashier receives the money, records the received amount by signature, and signs the receipt.

\section{Step 2: Rotate receipts}

The three copies of the collected slip are circulated as follows: Contact 1 is kept at the stalk, copy 2 is handed over to the depositor. If the person is outside the business, this bond is the basis to prove payment. If the person is in the enterprise, this bond will be given to the accounting department of that enterprise as a basis to prove that money was paid following the check.
Contact 3 cashiers to record the cash register; at the end of the day, gather the receipts with the attached original documents for the accountant to record the accounting books. Once recorded, the receipts are preserved for the year, and the year-end is transferred to the archival.

Step 3: The accountant makes a check

First, the payment slip is made into 3 copies by the payment accountant, put on a copy of the paper, and signed once. Then, transfer the check to the chief accountant and the head of the unit for approval. Finally, the cashier leaves the fund and signs the check. Step 4: Rotate the check

Payee, check, and sign the check. The three payment bonds are circulated as follows: Contact 1 saved at the stalk. Link 2 cashiers used to release the fund and record the cash register, then at the end of the day this link will be transferred to the accountant together with the original documents for accounting. After the checkbook is completed, the check will be put into preservation. Contact 3 assigned to the payee. In addition, businesses may need to deposit money into a bank, State Treasury or finance company to make non-cash payments during production and business. Invoices for accounting are credit notes, debit notes, or bank statements together with original invoices (collection authorization, payment order, transfer check). Upon receiving the bank's invoice, the accountant will compare the original invoice attached, notify the bank to compare, verify and promptly handle the difference.

\section{Cash accounting professional process}

General diagram (Figure 3):

Cash payment process (Figure 4):

\section{Cash Control Process}

Cash collection control process (Figure 5) :

Step 1: Receive payment documents.

Principle: The applicant offers to pay money. Payment accountants provide payment vouchers (vouchers) to ensure the reasonable and legality of the payer. Depending on the payment content, provide appropriate documents and documents.

Step 2: Present the chief accountant of the controlled documents.

Principle: The payment accountant is presented to the chief accountant for verification of the controlled documents.

The payment accountant must sign the controlled documents.

Step 3: Chief Accountant signs and approves the collection. 


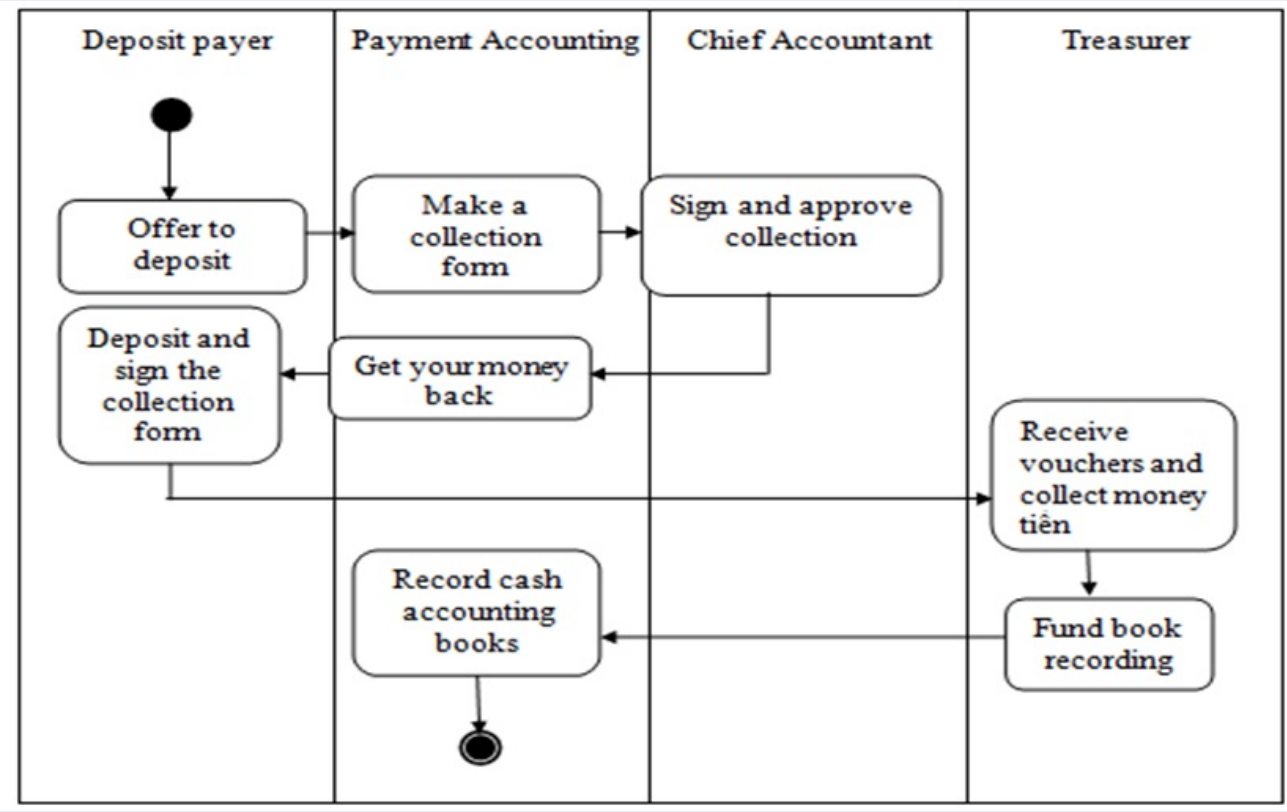

Figure 3: Cash collection process (Source: Design by the authors)

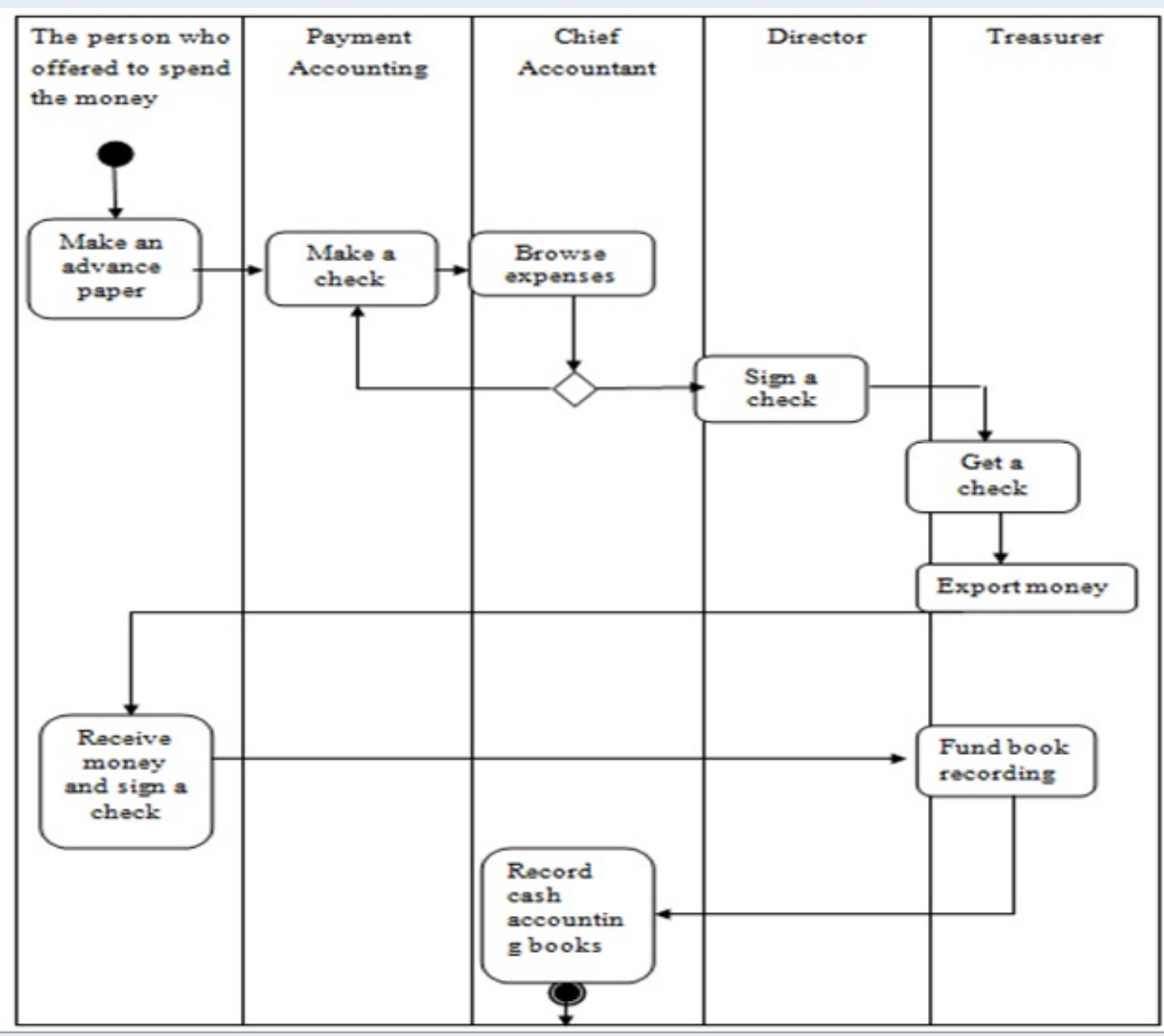

Figure 4: Cash expenditure business process (Source: Design by the authors) 


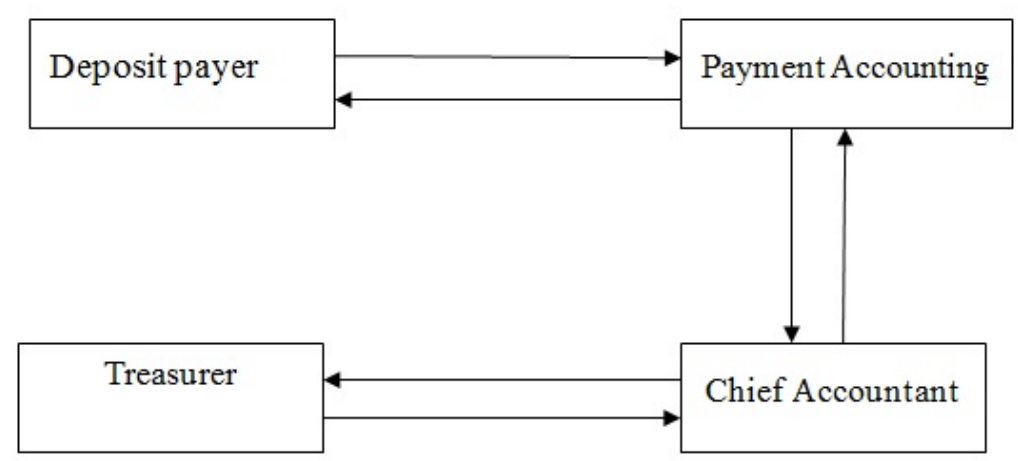

Notes:

$\rightarrow$ Directions

Directions of payment documents of controlled vouchers and payment

documents

Figure 5: Cash collection control process (Source: Design by the authors)

Principle: Vouchers are struck when the payment documents are fully signed by all departments involved in the process:

Petitioner

In charge of the department (Head of Administration

- General Department)

Payment Accounting

The chief accountant considers, if eligible, the documents and documents are transferred to the treasurer.

Step 4: The treasurer exports the payment.

Receive the collection form that has been fully signed by the relevant departments of the treasurer proceeding to collect the money. The payer and the fund deposit his/her name on the collection form.

The Treasurer enters the cash register of the cash treasurer the contents, date, number of vouchers, amount. Money expenditure control process (Figure 6) :

Step 1: Receive payment documents Principle: The administrative department provides full payment vouchers in terms of quantity, ensuring the reasonableness and legality for payment accounting. Depending on each payment content, it is required that the administrative department provide appropriate documents and documents.

Risks: Payment vouchers may not be in accordance with regulations, lack in quantity, and are not strict about the legality (including the reasonableness and legality). Control payment accountant lacks documents, does not guarantee legality, lost payment vouchers. Settlement is not guaranteed in terms of time.

Solution:

+ Stipulate the payment procedure, time, and process.

+ Request administrative staff to control documents before changing to accounting for payment following issued regulations.

+ The payment accountant strictly controls the documents they receive from the administration.

+ Sign for receipt of payment documents from the administrative handover party.

Step 2: Submit to the chief accountant the supervised accountant.

Principle: The payment accountant submits to the chief accountant to verify the controlled vouchers.

Risk: Payment vouchers may not ensure the legality, uncontrolled vouchers of payment accounting.

Solution :

+ Control the legality of the voucher.

The payment accountant must sign + Control documents.

Step 3: Submit to the Director for approval

Principle: The chief accountant has appraised the accountant submitted to the Director.

Risk: Payment vouchers may not ensure legality; the vouchers have not been assessed by the chief accountant. Measures: The chief accountant must sign appraised documents. 


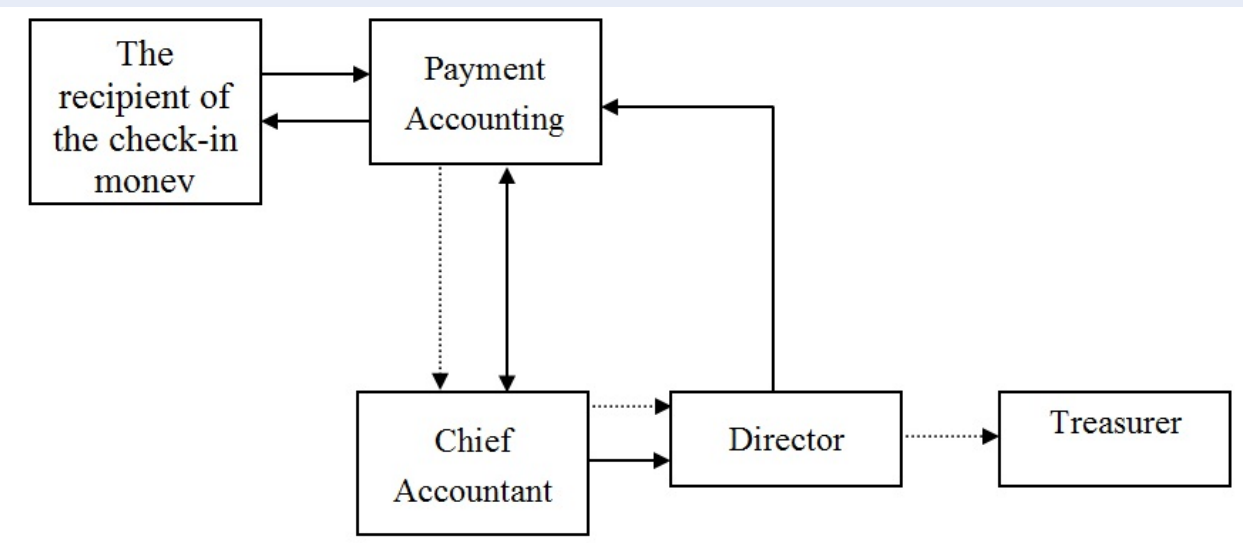

Notes:

$\rightarrow$ Directions of payment documents

Direction of checks, controlled payment documents

Figure 6: Cash disbursement process (Source: Design by the authors)

Step 4: The payment accountant prepares the payment slip with approved payment documents.

Principle: Payment vouchers are marked when the payment vouchers are fully signed by all the parts involved in the process:

+ Proponent

+ In charge of the department (Head of Administration - General)

+ Accounting payment

+ Director

Risk: Documentation lacks one or more of the process's link signatures. The contents of the payment note do not match the approved documents.

Solution Mark the check only when the above items fully sign the payment vouchers.

Before signing the check, you must compare the content and amount shown on the check with the payment voucher.

Step 5: Submit to the Chief Accountant to sign the check

Chief Accountant checks, if it is eligible for payment or advance, will sign and transfer documents to submit to the Director.

Step 6: Submit to the Director to sign the check.

The director considers, if eligible, signs the voucher, and the voucher is transferred to the cashier for payment.

Step 7: The cashier pays the payment.

Receiving vouchers and checks which related departments fully sign, the cashier checks again for the amount and content between the original voucher and the check to see if it is appropriate, then issue money is given to the person in the name of the check and both of you sign the check.

- The cashier transfers and returns 01 signed payment slip to the person in its name.

- The cashier enters into the cashier's cash book the contents, date, number of the payment slip, the amount of payment and then returns the voucher, 02 bills of payment for payment statement.

\section{Designing the process of digitization of documents stored at enterprises}

It can be said that managing documents, records, and documents is always the most time-consuming and challenging job in agencies and enterprises. By traditional methods, document management was often done manually, starting with the classification, arrangement, rearrangement of papers, monitoring books... then saving in the mail. Institute or archive, mark the code, record information in the clipboard to retrieve when needed. That leads to an overloaded management situation when the number of papers, documents, records, and official documents in the operation process increases greatly over time. In addition, manual management will need to have more measures to treat objective factors such as temperature and humidity, insects, mold... Longterm archives are often difficult to avoid being damaged, the original information is not clear, and timeconsuming searching and searching, reducing work 
efficiency. With documents going through the document digitization process, users can access information anytime, anywhere without limitation. Even many people can exploit and use a document at the same time easily. Furthermore, the longer the storage period is, the lower the quality of the archive for physical documents. Even these documents are likely to be damaged due to external factors such as moisture, mold, termites. Especially during use, they can also be lost by accidental users. The digitization of archives applied in enterprises is considered the optimal solution to help prolong documents' lives. Information is stored digitally to help businesses store as long as they want without worrying about document lifespan. In addition, the digitization of archived documents also makes it easier for users to recover and edit documents.

To save storage space, storage costs and restore documents, businesses need to digitized documents to improve the efficiency of document management, retrieval, sharing, and security. However, for optimization, businesses need to build digitizing archives, helping to convert information from paper documents to data forms that can be easily managed on a computer. After the enterprise successfully digitizes, all enterprise's documents will be pushed to a common management information system. As a result, significantly reduce the number of paper documents to be stored.

To carry out the digitization of documents at the enterprise, it is necessary to focus on three main components: computer software, devices that support digitization, and digitization services. Depending on the objectives and needs of digitizing documents of the business, the steps to implement the digitization process are also different. However, for the most common manner, businesses should still follow a 5-step process:

\section{Step 1: Collect archives:}

First of all, it is necessary to define electronic archives digitized from paper-based archives, Portable Document Format (.pdf), version 1.4 and above; color photo; Minimum resolution of $200 \mathrm{dpi}$; $100 \%$ digitization rate. The digital signature of the agency or organization manages digital archives: the upper right corner, the first page of the document; organ stamp image, organization, red, size equal to the actual size of the stamp, Portable Network Graphic (.png) format. Information includes the name of agency, organization, signing time (date, month, year; hour, minute, second; time zone of Vietnam according to ISO 8601). The file name includes the record code and the text number in the record, separated by dots.
Step 2: Prepare documents:

The jobs in this step include:

- Take out cardboard, staples; Flatten the document pages

- Classify documents, separate torn and damaged documents. Different scanning technique is applied based on the type of document; technique of scanning each document sheet for normal archival records. Document digitization applies new and more advanced technology such as Bookscan to bound archives.

\section{Step 3: System setup}

Scan and set up the imaging system; file name; set format; close, staple according to original document organization; create metadata (metadata). File formats are extensions at the end of a file name (file extension), indicating what format the file is in. The operating system uses the file extension information to open the appropriate program. Different image file formats provide different disk space, as well as image quality. The variables applied to image data files are: JPG, TIFF, GIF, PNG, RAW ... Each of these formats has its advantages and limitations.

In the digitizing archives process, this is the most decisive step for converting traditional documents into digital documents. A digital document catalog is compiled and embedded (attached) and documented through an application software and generated metadata. At the same time, the document is formatted according to a predefined selection.

\section{Step 4: Check the documentation:}

Document quality control digitized. If the quality of digitization is not met, it will be corrected to meet the requirements.

Step 5: Check, take over and hand over archived documents:

After digitizing is completed, the digitizing unit will hand over the original document to the business according to security requirements. The digital unit is also obliged to render and store information on the enterprise's storage system, such as servers, storage devices.

\section{CONCLUSION AND FUTURE WORK}

In the current development context, digital transformation does not just stop at retail, e-commerce, or information technology but has reached out to many different fields. In the context of the booming Covid19 epidemic, promoting digital transformation in enterprises is an online technology solution to optimize the management of business activities at enterprises. This article has codified the contents that need to be 


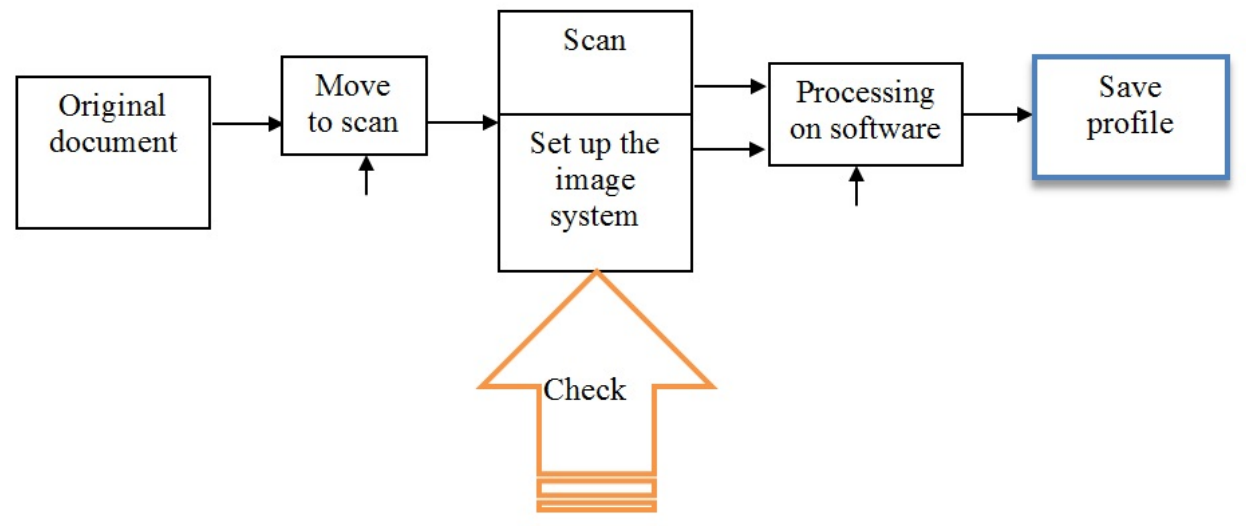

Figure 7: Digitization process diagram of documents stored at the enterprise (Source: Design by the authors)

digitally transformed in enterprises. The article analyzes and designs digitization of documents and operational processes to standardize the steps taken towards implementing digital transformation in enterprises. That will increase the efficiency of production, business, and management by creating, sharing ideas, proposing - reviewing, booking common resources, managing data, assets, and electronic form to eliminate waste and increase flexibility in the workflow. In addition, it also helps businesses overcome daily limitations such as employees who cannot grasp forms and papers at any stage of the process, what are shortcomings have not been resolved, the situation of losing time to dig. Create processes, submit forms for new employees. Or the problem of official documents, paper forms that have been printed and edited many times are no longer the same as the original; The person in charge of each stage takes more time to review and check. Therefore, businesses can direct remotely anytime, anywhere to avoid delaying project progress. With standardized electronic forms, all business documents are converted to digital format to help leaders and human resources create and handle work directly on paper cost erasing software, printing, indirect labor, etc... The process of digitizing documents will help businesses avoid the situation where records, applications from three copies are lost, errors in the creation and management of applications, forms. Thereby, businesses can seize opportunities to approach customers, focus on improving product quality to increase enterprise competitiveness. Besides, the article has also planned and designed the cash accounting module in the enterprises to handle transactions arising from cash income or expenditure. Proceed to prepare automatic payment slip receipts, update to the diary - ledger, cash register, cash collection diary, diary of payment.

However, the study only focuses on clarifying that one of the 5 steps of implementing digital transformation in enterprises is to digitize documents and processes. Therefore, in the next research, the author will continue to analyze and design operational processes and clarify the remaining work contents to complete the digital transformation stages for application in enterprises. From there, help optimize management and improve operational efficiency for businesses.

\section{COMPETING INTERESTS}

The authors declare that they have no known competing financial interests or personal relationships that could have appeared to influence the work reported in this paper.

\section{AUTHORS' CONTRIBUTIONS}

Manh Tuan Nguyen: Write the content of the article summary and the introduction to digital transformation in businesses

Quoc Hung Nguyen: Write the contents of the research literature review and the conclusion

Thi Hang Nguyen: Write the contents of the research methodology and design of the cash accounting process to perform digital transformation at the enterprise.

\section{REFERENCES}

1. Marshall RM. Determining an optimal accounting information system for an unidentified user. Journal of Accounting Research. 1972;p. 286-307. Available from: https://doi.org/10. $2307 / 2490010$. 
2. Otley DT. The contingency theory of management accounting: achievement and prognosis. In Readings in accounting for management control. Springer. 1980;p. 83-106. Available from: https://doi.org/10.1007/978-1-4899-7138-8_5.

3. Gordon LA, Narayanan VK. Management accounting systems, perceived environmental uncertainty and organization structure: an empirical investigation. Accounting, Organizations and Society. 1984;9(1):33-47. Available from: https://doi.org/ 10.1016/0361-3682(84)90028-X.

4. Kim E, Lee J. An exploratory contingency model of user participation and MIS use. Information \& Management. 1986;11(2):87-97. Available from: https://doi.org/10.1016/ 0378-7206(86)90038-8.

5. Susanto $A$. What factors influence the quality of accounting information. International Journal of Applied Business and Economic Research. 2015;13(6):3995-4014.

6. Neogy D. Evaluation of efficiency of accounting information systems: A study on mobile telecommunication companies in Bangladesh. Global Disclosure of Economics and Business. 2014;3(1). Available from: https://doi.org/10.18034/gdeb.v3i1. 170.

7. Alzoubi A. The effectiveness of the accounting information system under the enterprise resources planning (ERP). Research Journal of Finance and Accounting. 2011;2(11):10-19.

8. Botta-Genoulaz V, Millet PA. An investigation into the use of ERP systems in the service sector. International journal of production economics. 2006;99(1-2):202-221. Available from: https://doi.org/10.1016/j.ijpe.2004.12.015.

9. Belfo F, Trigo A. Accounting information systems: Tradition and future directions. Procedia Technology. 2013;9:536-546. Available from: https://doi.org/10.1016/j.protcy.2013.12.060.

10. Budiarto DS, Prabowo MA. Accounting information systems alignment and SMEs performance: A literature review. International Journal of Management, Economics and Social Sciences. 2015;4(2):58.

11. Ezzamel M, Bourn M. The roles of accounting information systems in an organization experiencing financial crisis. Accounting, Organizations and Society. 1990;15(5):399-424. Available from: https://doi.org/10.1016/0361-3682(90)90025-P.
12. Davenport TH. Putting the enterprise into the enterprise system. Harvard business review. 1998;76(4).

13. Holland C, Light B. A critical success factors model for ERP implementation. IEEE software. , (3), - . 1999;16(3):30-36. Available from: https://doi.org/10.1109/52.765784.

14. Nah FFH, et al. ERP implementation: chief information officers' perceptions of critical success factors. International journal of Human-computer Interaction. 2003;16(1):5-22. Available from: https://doi.org/10.1207/S15327590IJHC1601_2.

15. Wheeler PR, et al. Accounting Information Systems Research Opportunities Using Personality Type Theory and the Myers-Briggs Type Indicator. Journal of information systems. 2004;18(1):1-19. Available from: https://doi.org/10.2308/jis. 2004.18.1.1.

16. Azmi F, Sri M. Factors that affect accounting information system success and its implication on accounting information quality. SIMILIARITY. 2020;

17. Grabski SV, et al. A review of ERP research: A future agenda for accounting information systems. Journal of information systems. 2011;25(1):37-78. Available from: https://doi.org/10. 2308/jis.2011.25.1.37.

18. Ghasemi M, Shafeiepour V, et al. The impact of Information Technology (IT) on modern accounting systems. ProcediaSocial and Behavioral Sciences. 2011;28:112-116. Available from: https://doi.org/10.1016/j.sbspro.2011.11.023.

19. Chalu H. Analysis of stakeholder factors influencing the effectiveness of accounting information systems in Tanzania's local authorities. Business Management Review. 2015;16(1).

20. Kumar K, Hillegersberg JV. ERP experiences and evolution. Communications of the ACM. 2000;43(4):22-22. Available from: https://doi.org/10.1145/332051.332063.

21. Wei KS, et al. Measuring ERP system success: a respecification of the Delone and McLean's IS success model. Paper presented at the Symposium on progress in information \& communication technology. 2009;.

22. Weinelt B, Moavenzadeh J. Digital Transformation Initiative Aviation, Travel and Tourism Industry. World Economic Forum 91-93 route de la Capite $\mathrm{CH}-1223$ Cologny/Geneva Switzerland. 2017; 